\title{
BMJ Open Mortality and readmission following hip fracture surgery: a retrospective study comparing conventional and fast- track care
}

Kristin Haugan, ${ }^{1}$ Lars G Johnsen, ${ }^{1,2}$ Trude Basso, ${ }^{1}$ Olav A Foss ${ }^{1}$

To cite: Haugan K, Johnsen LG, Basso $\mathrm{T}$, et al. Mortality and readmission following hip fracture surgery: a retrospective study comparing conventional and fast-track care. BMJ Open 2017;7:e015574. doi:10.1136/ bmjopen-2016-015574

- Prepublication history for this paper is available online. To view these files, please visit the journal online (http://dx.doi. org/10.1136/bmjopen-2016015574).

Received 16 December 2016 Revised 8 June 2017 Accepted 26 July 2017

\section{(a) CrossMark}

${ }^{1}$ Department of Orthopaedics, Orthopaedic Research Centre, St Olavs Hospital, Trondheim University Hospital, Trondheim, Norway

${ }^{2}$ Department of Neuromedicine and Movement Science,

Norwegian University of

Science and Technology, NTNU, Trondheim, Norway

Correspondence to

Kristin Haugan;

kristin.haugan@ntnu.no

\section{ABSTRACT}

Objective To compare the efficacies of two pathwaysconventional and fast-track care-in patients with hip fracture.

Design Retrospective single-centre study. Setting University hospital in middle Norway. Participants 1820 patients aged $\geq 65$ years with hip fracture (intracapsular, intertrochanteric or subtrochanteric).

Interventions 788 patients were treated according to conventional care from April 2008 to September 2011, and 1032 patients were treated according to fast-track care from October 2011 to December 2013.

Primary and secondary outcome Primary: mortality and readmission to hospital, within 365 days follow-up. Secondary: length of stay.

Results We found no statistically significant differences in mortality and readmission rate between patients in the fast-track and conventional care models within 365 days after the initial hospital admission. The conventional care group had a higher, no statistical significant mortality HR of $1.10(95 \% \mathrm{Cl} 0.91$ to $1.31, \mathrm{p}=0.326)$ without and 1.16 (95\% Cl 0.96 to $1.40, p=0.118$ ) with covariate adjustment. Regarding the readmission, the conventional care group sub-HR was $1.02(95 \% \mathrm{Cl} 0.88$ to $1.18, \mathrm{p}=0.822)$ without and $0.97(95 \% \mathrm{Cl} 0.83$ to $1.12, \mathrm{p}=0.644)$ with adjusting for covariates. Length of stay and time to surgery was statistically significant shorter for patients who received fast-track care, a mean difference of 3.4 days and 6 hours, respectively. There was no statistically significant difference in sex, type of fracture, age or Charlson Comorbidity Index score at baseline between patients in the two pathways.

Conclusions There was insufficient evidence to show an impact of fast-track care on mortality and readmission. Length of stay and time to surgery were decreased. Trial registration number NCT00667914; results

\section{INTRODUCTION}

Elderly patients, aged 50 years or older, with a hip fracture have an increased risk of mortality and comorbidity. ${ }^{1-3}$ While a $25 \%$ mortality rate was reported at 12 months, ${ }^{4}$ another study reported an increased mortality risk 10 years after the fracture. ${ }^{5}$ Comorbidity and
Strengths and limitations of this study

- Wide inclusion criteria, including also the most fragile patients.

- The almost complete data set with few missing data.

- Retrospective design.

- Data collected in two different periods of time

- Lacks data for dwelling before admission and after discharge.

general frailty makes these patients especially vulnerable to trauma such as a hip fracture. ${ }^{6}$

There is no consensus regarding the most beneficial treatment factors to optimise outcomes after hip fracture surgery, but in the last 15 years, guidelines have focused on factors to optimise the care involved. ${ }^{7}$ Early surgery is considered a key factor to reduce subsequent mortality risk. ${ }^{8-10}$ Early mobilisation may lessen mortality, length of stay (LOS) and further postoperative hospitalisation. ${ }^{11-14}$ The LOS differs between studies and the effect is not consistent, some show that prolonged LOS may increase readmissions after discharge,${ }^{1516}$ and others find that a reduction in LOS increase mortality. ${ }^{17}$

The incidence of hip fractures in Norway is high, like in other Scandinavian countries. $^{18-20}$ So far, the majority of patients in Norway are treated with a low surgical priority and extended hospitalisation.

Fast-track care is a way of organising clinical pathways using principles from lean methodology. ${ }^{21}$ The key concept is standardisation of all routines in the clinical pathway: priority to surgery, standardised surgical techniques, improved pain control and early mobilisation. ${ }^{22}{ }^{23}$ However, different hospitals employ different aspects of the fast-track system. ${ }^{22}$ Fast-track care for patients with hip fracture was established at the St Olavs Hospital, Trondheim University Hospital, Norway, in 2011 and included surgical priority, early 
mobilisation, medication reconciliation and a standardised treatment from admission to discharge.

The primary aims of this study were to compare the mortality and readmission rate within 365 days after a hip fracture in patients allocated to either conventional or fast-track care. The secondary aim was length of stay.

\section{METHODS}

\section{Study design}

This was a single-centre retrospective study carried out at St Olavs Hospital, University Hospital in Trondheim, Norway, primary hospital for 300000 inhabitants in the middle of Norway that treats approximately 400 hip fractures yearly. In Norway, all hip fracture patients are treated in public hospitals.

\section{Study population}

The study included a total of 1820 patients undergoing hip fracture surgery between April 2008-September 2011 (conventional care) and October 2011-December 2013 (fast-track care).

Inhospital data were obtained from our internal hip fracture quality register, manually reviewed medical records and partly the Trondheim Hip Fracture Trial study (HFT) ${ }^{1424}$ Retrospective data up to 365 days after discharge were collected by manually reviewing medical records. Only readmissions to Trondheim University Hospital were registered, because data from other hospitals were not available. Permanent residents of Norway could be identified by their 11-digit personal identification number. Patient identity was used to collect medical history from administrative databases and reported deaths.

\section{Inclusion and exclusion criteria}

Our inclusion criteria were as follows: patients aged $\geq 65$ years, with an intracapsular, intertrochanteric or subtrochanteric hip fracture admitted and undergoing surgery at the University Hospital. Patients fulfilling these criteria were included irrespective of comorbidity, dwelling or short lifetime prognosis. The study was approved by the Regional Committee of Ethics in Medical Research and participant consent was not required.

Only data from the patient's first hip fracture in the study period were included in the hip fracture analysis. Any subsequent hip fracture was included as a readmission along with other causes of readmission. Twenty-one patients geographically belonging to other hospitals underwent surgery at our hospital. Readmission data for these were not available and registered as 'missing' in the readmission analysis.

The total number of patients along with the detailed inclusion and exclusion criteria is presented as a flow chart (figure 1). The HFT study was conducted at our hospital from 2008 to 2010. The present study has wider inclusion criteria than the HFT. In the HFT the sickest patients, defined as patients with pathological fractures, a short-life expectancy or living permanently in nursing homes, were excluded. If all of the sickest were considered as eligible in the present study, we would end up with a skewed population with an over-representation of the sickest. To adjust for this, we randomly excluded $50 \%$ of the sickest patients in the

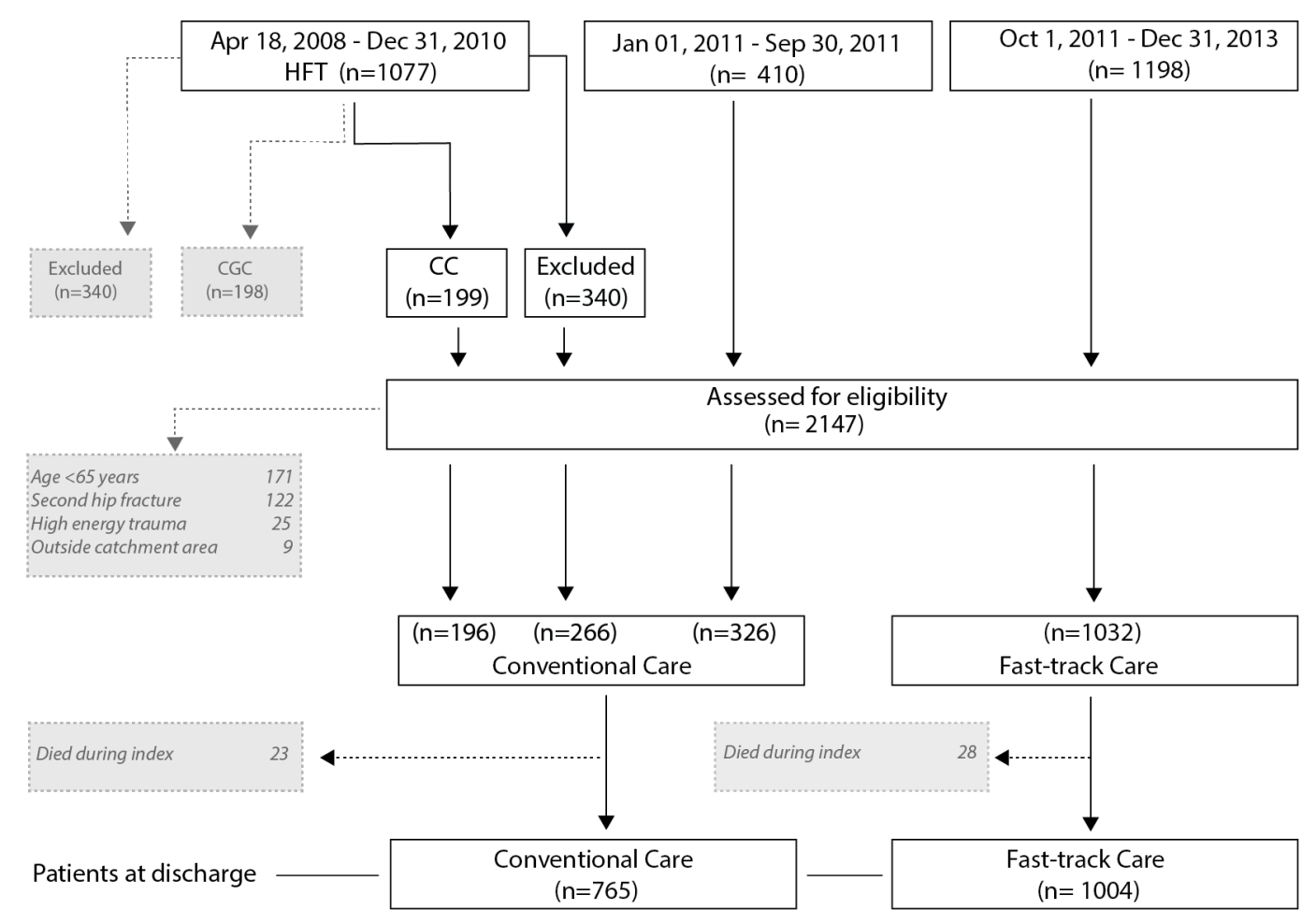

Figure 1 Flow chart. CC, conventional care; CGC, comprehensive geriatric care; HFT, Hip Fracture Trial. 
time-period 2008-2010 from eligibility to re-establish a representative population. Neither patients in the HFT who were randomised to comprehensive geriatric care were eligible to our study.

\section{Comorbidity indices}

We used the Charlson Comorbidity Index (CCI) score to control for equality in health between the two groups. ${ }^{25}$ The coding algorithm developed by Quan identified the comorbidities and defined the weight score, ranging from 0 to $24 .{ }^{26}{ }^{27}$ The present CCI scores were based on all 10th revision of the International Classification of Diseases (ICD10) diagnosis codes occurring in the last 3 years prior to and including the current episode, partly based on the standards from the Norwegian Knowledge Centre for the Health Services. ${ }^{28}$ Both main and secondary diagnoses (ICD-10), with no limitations to the number, were registered.

Both comorbidity and age may predict probability of death. The Charlson Comorbidity-Age Index (CCAI) score $^{2529}$ is calculated by adding one point for each decade from the time the patient turns 50 years old to adjust for age. Both indices were calculated, only the CCI score was used in the regression analysis.

\section{The pathways}

\section{Conventional care}

Patients were at first examined by a general practitioner at the site of the injury. The patient was then transported by ambulance to the emergency unit for another examination by an orthopaedic resident on call, sent to the radiology department and subsequently back to the emergency unit. Finally (and very often after 3-4hours of waiting time), the patient was brought to the orthopaedic ward. Nursing routines (pain control, nutrition, fluid therapy and prevention of pressure sores) were then initiated. Prolonged waiting time for surgery was often the result as patients with hip fractures were not prioritised for surgery. Very few treatment procedures were standardised and designed for this special patient group. Surgery was often performed between 23:00 and 8:00. There was no strict mobilisation regimens to ensure mobilisation first postoperative day.

\section{Fast-track care}

The fast-track care were started at the site of injury, on arrival of the ambulance personnel. They examined the patient and directly reported to the hospital with a tentative diagnosis of 'hip fracture' without contacting a practitioner. Preoperative treatment like administration of morphine, oxygen and prevention of pressure sores was started. The patient was transported directly to the radiology department, and further on to the orthopaedic ward, all by the ambulance personnel. On arrival at the orthopaedic ward, standardised nursing routines (pain control, nutrition, fluid therapy and prevention of pressure sores) were begun. Regional anaesthesia in the form of a femoral block were established, while an orthopaedic resident on call examined the patient. All patients with hip fracture were scheduled for surgery within 24hours (although not between 22:00 and 8:00). Preparation for discharge was started on the day of admission and thus the coordination with the municipal health service had an early start. Whenever possible, all patients were mobilised on the first postoperative day with a physiotherapist. Wardbased pharmacists evaluated the medication lists by using the method of medication reconciliation. ${ }^{30} 31$

To summarise the differences between the two pathways: for the conventional care there was no preoperatively scheduled time for surgery. The preoperative and postoperative pain control and postoperatively mobilisation regimens were not standardised.

For the fast-track care, there were scheduled surgery within 24 hours, early preparation of discharge, standardised preoperative and postoperative pain control, standardised mobilisation on first postoperative day and medication reconciliation.

Both pathways had similar discharge criteria; when the orthopaedic surgeon conclude there is no need for further medical assessment or treatment in the specialist health services.

\section{Hip fracture surgery implants}

For intracapsular fractures, hip screws were mostly used until 2008. After this time, a bipolar, cemented hemiprosthesis has most often been used for this fracture type. ${ }^{732}$ For intertrochanteric fractures, sliding hip screws were used, and for subtrochanteric fractures, intramedullary nailing or sliding hip screws were used.

\section{Primary outcomes}

\section{Mortality}

The follow-up time was 365 days. Time to death was calculated from admission to possible event. The specific mortality rate at 30 days, 90 days and 365 days follow-up are also reported.

\section{Readmission}

The follow-up time was 365 days. A readmission was registered as such if unplanned hospitalisation occurred more than 8 hours after discharge of the previous admission. Reason for readmission was based on the primary diagnosis (ICD 10). The readmission rates specific to the 30 days, 90 days and 365 days follow-up are reported.

\section{LOS}

LOS was defined as the number of days between admission and discharge from the hospital. If the patient was treated at another or several hospital departments after the fracture, the total number of treatment days were counted.

\section{Secondary outcome}

\section{Time to surgery}

Time to surgery (TTS) was calculated as hours from hospital admission to surgery, as the exact time of the fracture was unknown.

\section{Statistical analysis}

The analyses were performed using Stata V.14 (StataCorp). The command 'Sample' was used to exclude 
a randomised $50 \%$ portion of the sickest patients in the time period 2008-2010.

Visual inspection of $\mathrm{Q}-\mathrm{Q}$ plots was used to evaluate normality of data. Independent-samples t-test was used for normally distributed data (age), Wilcoxon rank-sum test for non-normally distributed data (CCI score, CCAI score, TTS, surgery time and LOS) and Pearson $\chi^{2}$ tests were used for categorical data (sex and type of hip fracture, anaesthesia and implant).

In the following two models, covariates were included in the analyses. The selection of covariates was based on clinical considerations. Cox proportional hazards regression (command, stcox) was used to analyse patient mortality hazards and competing risks regression (command, stcrreg) to analyse the hazards of readmission. The time variable, calculating mortality hazards was the number of days from hospital admission to possible death. Calculating the readmission hazards, the time variable was the number of days from hospital discharge to a possible first readmission. The follow-up times were maximum 365 days, respectively. Death was considered as the competing event when analysing the readmission hazards. The dataset was complete when analysing the mortality hazards and with 21 missing patients analysing the readmission hazards. The Cox proportional hazards assumptions was verified $(\mathrm{p}=0.167)$ (command, estat phtest). Visual inspection of Plots of Schoenfeld residuals was used to verify the proportional hazard assumptions of the competing risks regression. ${ }^{33}$ The proportional mortality hazards and hazards of readmission was first calculated without the inclusion of covariates and then with CCI score, age, sex, LOS, type of hip fracture and type of implant as covariates. The calculated $p$ values were two tailed, $\mathrm{p}<0.05$ was considered statistical significant.

\section{RESULTS}

Of the total 1820 patients included, 788 were treated according to conventional care and 1032 patients according to fast-track care. There were no statistically significant differences between the groups according to baseline characteristics, sex, fracture type, age at admission, CCI score and CCAI score (table 1).

Fifty-one patients (2.8\%) died during index stay: 23 persons in the conventional care $(2.9 \%)$ and 28 persons in the fast-track care (2.7\%) groups. Further, 472 patients died within the first year after admission: 213 belonged to the conventional care group and 259 to the fast-track care group. Mortality data are presented in table 2, and the Cox proportional hazards regression are presented in figure 2.

The conventional care group had a higher, no statistical significant mortality HR of 1.10 (95\% CI 0.91 to $1.31, \mathrm{p}=0.326)$ without and 1.16 (95\% CI 0.96 to 1.40 , $\mathrm{p}=0.118$ ) with covariate adjustment. The effects of care, CCI score, patient's age, sex, LOS, type of fracture and type of implant are presented in table 3.

Within 30 days after discharge, 103 patients were readmitted in the conventional care group and 155 patients in the fast-track care group. Further, 725 patients were readmitted within first year, 319 patients in the conventional and 406 patients in the fast-track care group. Readmission data are presented in table 2 , and the competing risk regression are presented in figure 3 .

Table 1 Baseline patient characteristics

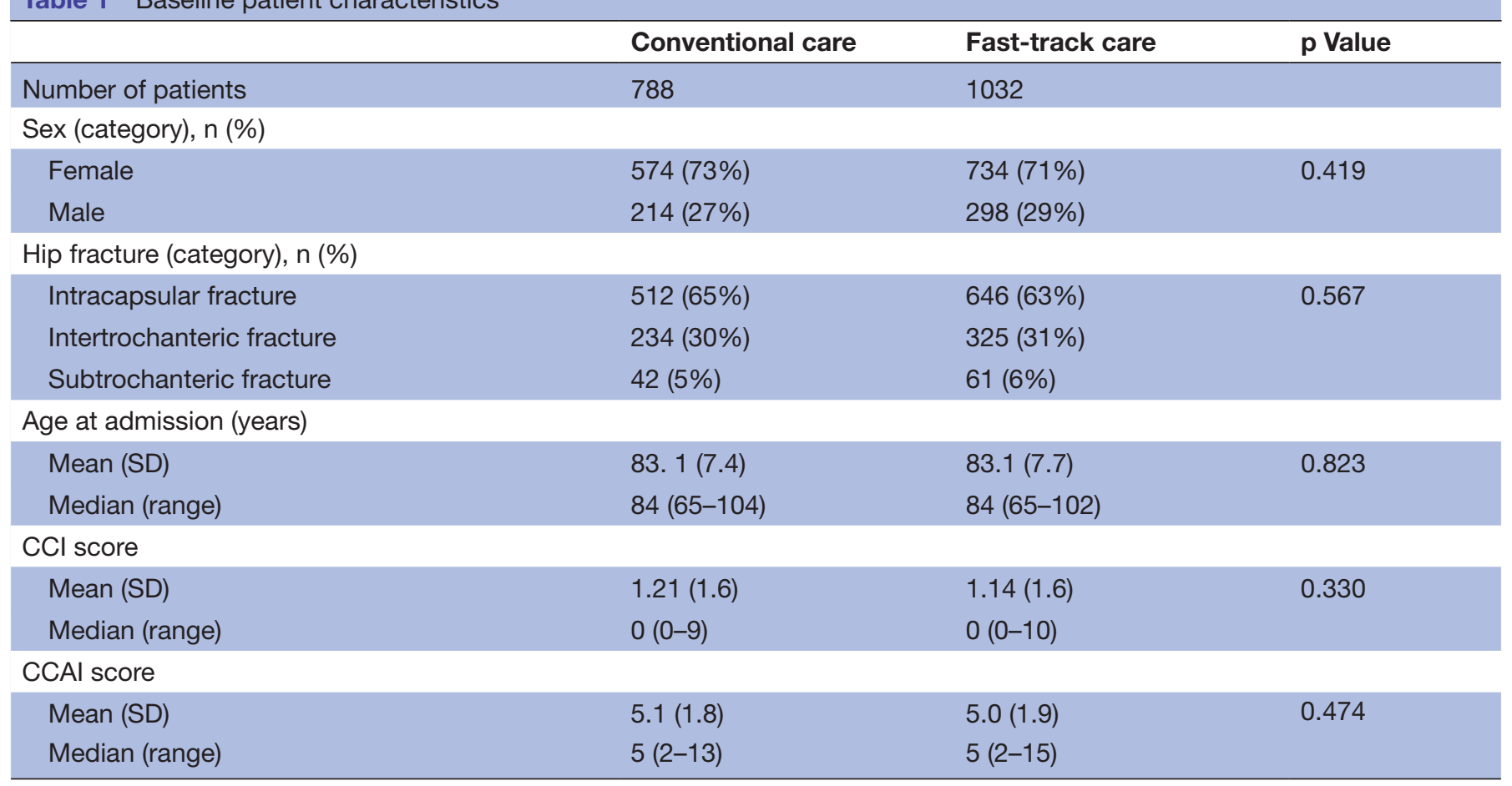

CCAI, Charlson Comorbidity-Age Index; CCI, Charlson Comorbidity Index. 
Table 2 Mortality and readmission rates within 365 days after the index hip fracture discharge

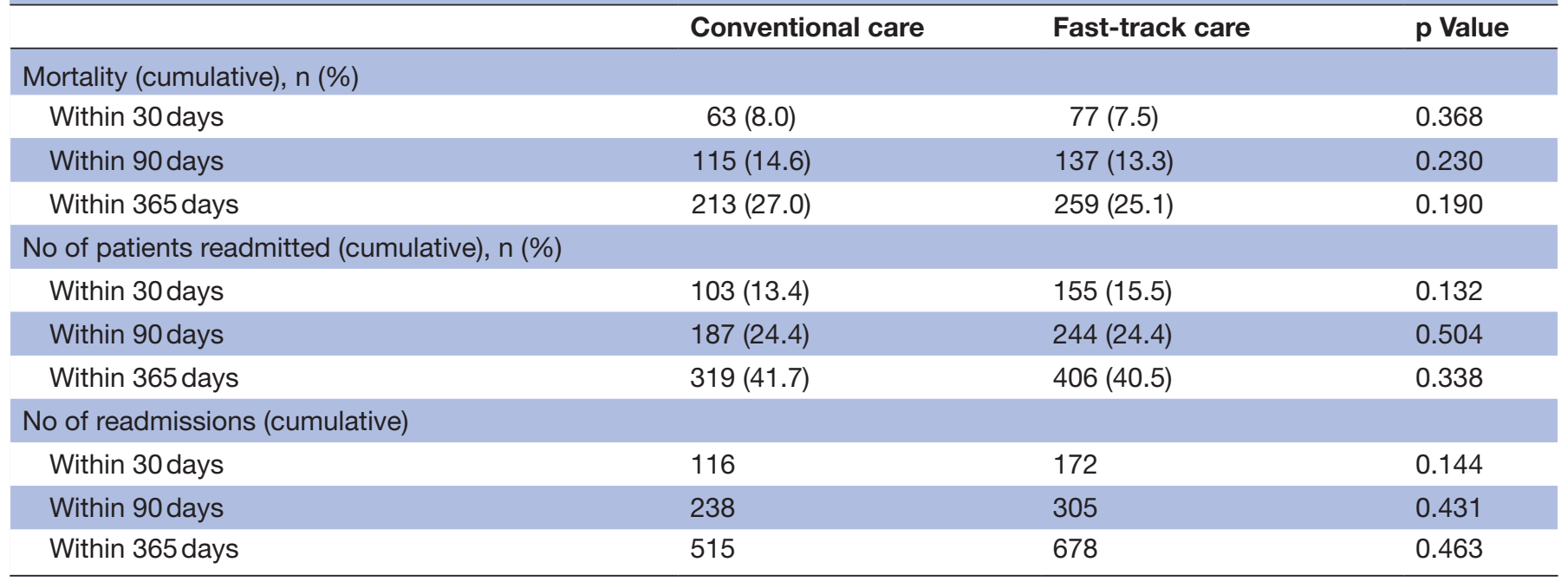

The competing risks proportional subhazards of the number of days to first readmission showed no statistical differences between the two groups. The conventional care group sub-HR was 1.02 (95\% CI 0.88 to 1.18 , $\mathrm{p}=0.822)$ without and 0.97 (95\% CI 0.83 to $1.12, \mathrm{p}=0.644)$ with adjusting for covariates. The effects of the covariates are presented in table 3 .

The results regarding TTS, surgery time together with types of anaesthesia, implants and LOS are presented in table 4 . TTS was 6 hours longer for patients who received conventional care. The use of anaesthesia did not differ between the two groups. Surgery time was $4 \mathrm{~min}$ shorter for patients who received conventional care. There was an overall statistically significant difference in the use of implants between the two groups $(p=0.02)$. LOS was 3.4 days shorter in the fast track care group.

The most frequent reason for first readmission within 30 days after the index stay in the fast-track care group was postoperative wound infection $(\mathrm{n}=20[12.9 \%])$ and pneumonia $(n=13[8.4 \%])$. In the conventional care group, pneumonia was the most frequent $(n=11(10.7 \%))$,

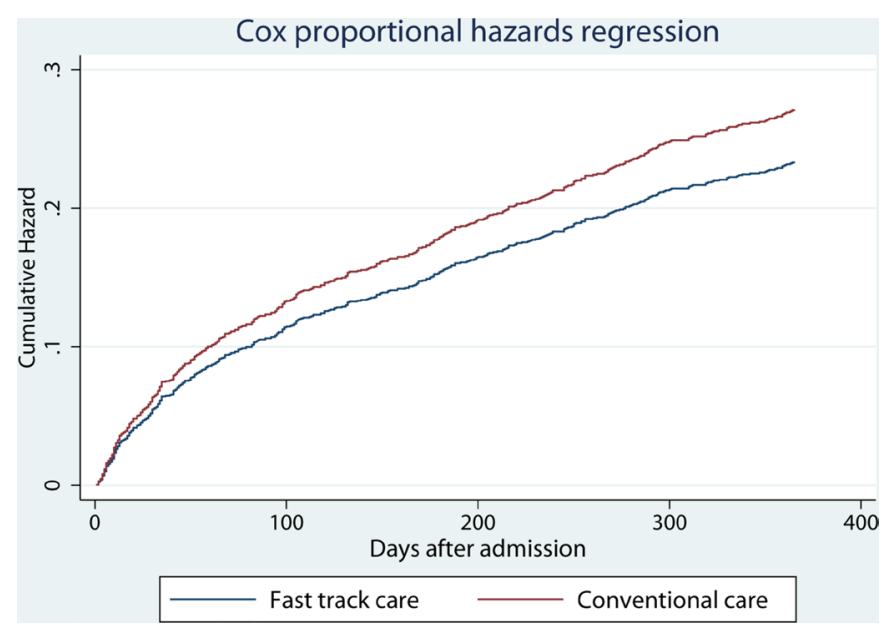

Figure 2 Cox proportional hazards regression. followed by postoperative wound infection and cardiac disease (both $\mathrm{n}=7(6.8 \%))$.

\section{DISCUSSION}

We found no statistically significant difference in mortality and readmission rate for patients in the fast-track care compared with conventional care within 12 months after hospital admission. We found a statistically significant decrease of approximately 6 hours in TTS and 3.4 days in LOS. Baseline patient characteristics were similar.

Table 3 HR of mortality within 365 days after admission and number of days to first readmission within 365 days after discharge

\begin{tabular}{llllr}
\hline & HR & 95\% CI & p Value \\
\hline Mortality & & & & \\
\hline Conventional care & 1.16 & 0.96 & 1.40 & 0.118 \\
\hline CCl score & 1.38 & 1.33 & 1.44 & $<0.001$ \\
\hline Age & 1.07 & 1.05 & 1.08 & $<0.001$ \\
\hline Male sex & 1.46 & 1.20 & 1.77 & $<0.001$ \\
\hline LOS & 0.99 & 0.98 & 1.00 & 0.182 \\
\hline Type of fracture & 1.06 & 0.91 & 1.23 & 0.476 \\
\hline Type of implant & 1.03 & 0.97 & 1.09 & 0.401 \\
\hline Readmission & & & & \\
\hline Conventional care & 0.97 & 0.83 & 1.12 & 0.644 \\
\hline CCl score & 1.05 & 1.00 & 1.09 & 0.043 \\
\hline Age & 1.01 & 1.00 & 1.02 & 0.020 \\
\hline Male sex & 1.22 & 1.04 & 1.44 & 0.014 \\
\hline LOS & 1.01 & 1.00 & 1.02 & 0.004 \\
\hline Type of fracture & 0.91 & 0.81 & 1.04 & 0.192 \\
\hline Type of implant & 1.07 & 1.02 & 1.11 & 0.006 \\
\hline
\end{tabular}

$\mathrm{CCl}$, Charlson Comorbidity Index; LOS, length of stay. 


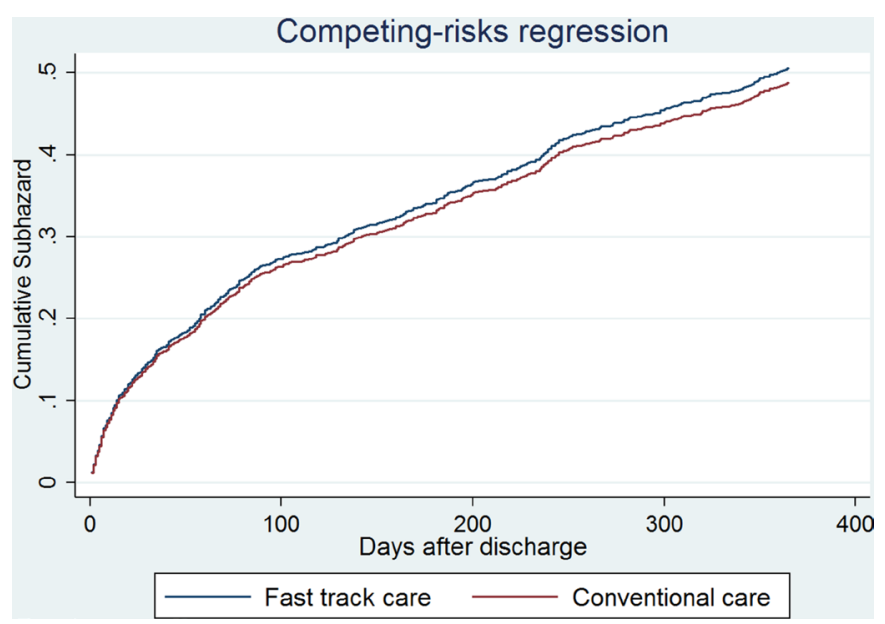

Figure 3 Competing risks regression.

A Danish study compared results before and after introduction of fast-track and found a decrease in TTS, into 26.4 hours, a shorter LOS, 9.7 days, a reduction in inhospital postoperative complications and a trend towards a lower mortality, a 12-month rate of $23 \%$, after introduction of the fast-track treatment. ${ }^{34}$

The reduced TTS and LOS in the fast-track care group in our study are results from improved treatment and organizational factors, both pre- and postoperatively. The preoperative alterations was change in pain control, standardisation of nursing routines, nutrition, fluid therapy and early surgery. Postoperatively the changes included standardisation of pain control and early mobilization. The organisational factors were medication reconciliation and early preparation of discharge, the latter to avoid delay by organisational reasons. The interaction of clinical and organisational factors can affect LOS. ${ }^{35}$
The reduced TTS can only partly explain the reduced LOS in the present study. But, the early surgery, efficient pain relief, mobilisation on the first postoperative day and early cooperation with the municipal help service to arrange for rehabilitation in an institution or the patient's own home are elements that can contribute to a shorter LOS. The National Institute for Health and Care Excellence guidelines recommend an early supported discharge for care home and nursing home patients to ensure a systematic approach to rehabilitation. ${ }^{7}$ An efficient pain relief may allow an early mobilisation which is considered to be an essential part of the rehabilitation process. ${ }^{36}$ A Danish hip fracture study found that patients following a fast-track performance had lower odds of readmission at 30 days $(17.4 \%)$; their results were associated with early mobilisation, systematic pain assessment and antiosteoporotic medication. ${ }^{37}$

The use of implant differed between the two groups because of the general shift from hip screws to hemiprostheses treating intracapsular fractures, in line with published recommendations. ${ }^{38}$ Both the type of hip fracture and type of implants were included as covariates when analysing the hazards. The effect of differences in the use of implant between the two groups should therefore be minimised.

The increase in use of hemiprostheses and a subsequent reduction in use of hip screws, can likely explain the increase in surgery time in our fast-track care. Use of spinal anaesthesia is higher in Norway than in other countries. ${ }^{22}{ }^{34}$ There is no evidence that spinal anaesthesia decreases the mortality risk or eases the recovery of the patient, ${ }^{3940}$ one study found an increase in LOS after non-general anaesthesia, ${ }^{41}$ a review found a modestly shorter LOS. ${ }^{40}$

Table 4 Outcome measures; time to surgery, anaesthesia type, implant type, surgery time and length of stay

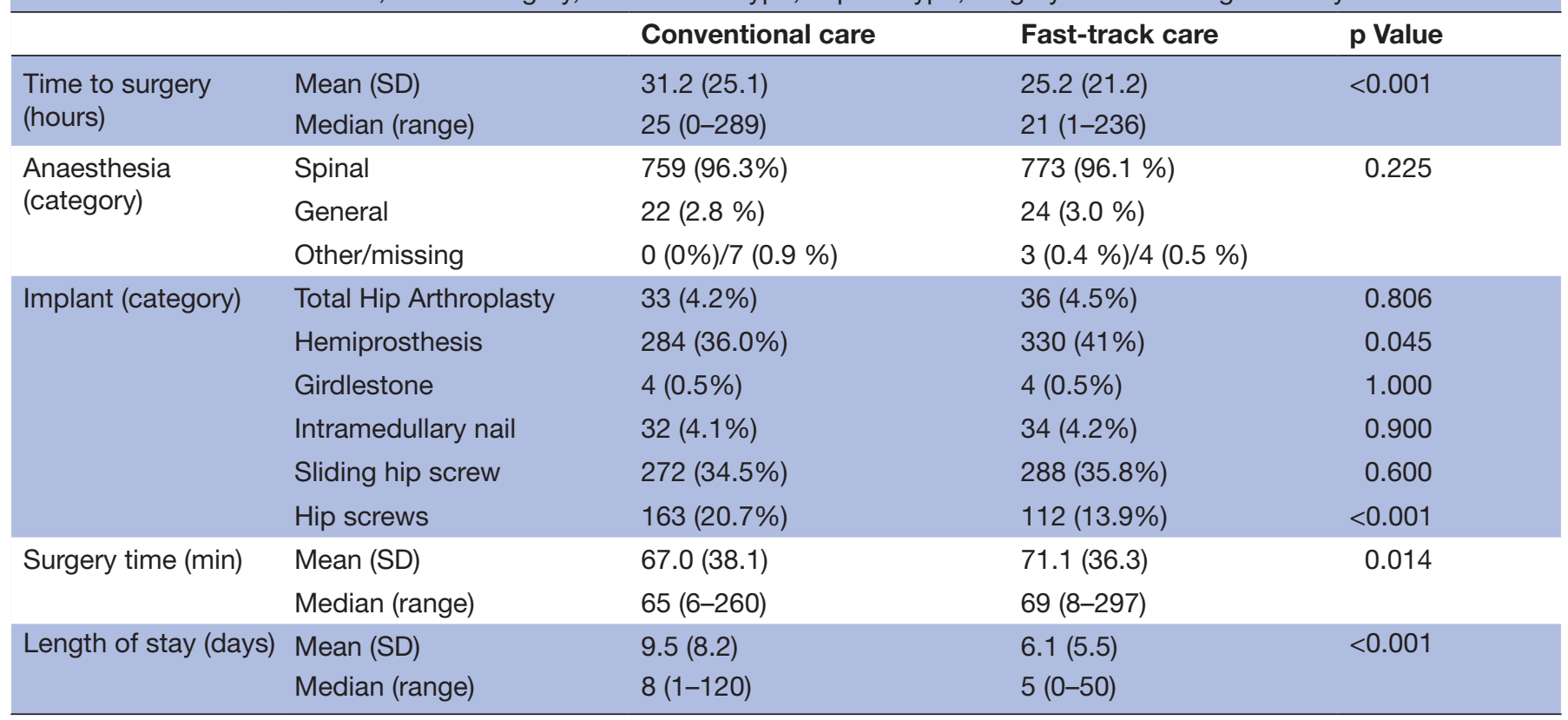


We are yet unsure if the switch to merely day-shift surgery has an impact on outcome. One could assume a reduction in complications, though we did note a small increase in the postoperative wound infection in the fast-track group. A comparison ${ }^{42}$ of day-shift and night-shift surgery did not find any higher postoperative complication rate in nightshift surgery, but the study size was small, which could have affected the result. Introduction of day-shift surgery and a reduction of TTS indicate that fast-track care at our hospital improved the efficiency of care and were beneficial to both patients and staff. The medication reconciliation may reduce medical side effects, such as dizziness, nausea and prevent new falls from occurring and was therefore included as an element in our fast-track care.

The critical factors for mortality are increased CCI score, older age and male sex, the critical factor for readmission is an increased LOS, even if the effect is small. In our study, the most common cause for first readmission within 30 days in the fast-track care group was wound infection, while pneumonia was the most common cause in the conventional care group.

Priority for surgery and a standardised treatment is beneficial for these vulnerable patients. Less night-shift surgery, less hospital beds filled and reduced LOS without increasing serious complications is beneficial for the healthcare system. We find the factors included in our fast-track concept favourable.

\section{Strengths and limitations}

The strengths of the study are the almost complete data set, with few missing data; prior to, inhospital and after surgery and our extensive inclusion criteria; including all patients 65 years and older, irrespective of health status. It is known that the Kaplan-Meier estimator may overestimate the probability of events of interest when competing risks are present. Therefore, death was included as a competing event when analysing the readmission hazards. ${ }^{43}$

There are limitations to our study, mainly owing to its retrospective design. A randomised comparison of the two pathways was not feasible as both care models could not be run at the same time because of practical hospital considerations. There was no difference in baseline characteristics of fracture types or patient's characteristics, justifying our comparisons across two time periods. Only the readmissions to our hospital were registered. Because most of the included patients geographically belonged to this hospital and had a very low geographical mobility, we assumed that most of the readmissions would be to our hospital and thus, registered. Other limitations are that the calculation of TTS is from the time of hospital admission and not from the actual fracture time and the lack of data for dwelling before admission and after discharge.

\section{CONCLUSION}

The results was insufficient to show an impact of fast-track care on mortality and readmission. The core of our study was the reduction in TTS and LOS without increasing mortality and readmission rates in the fast-track care model.

Further work should focus on patients' discharge location, if the decrease in LOS could be a result of a change in the rehabilitation care, and it should explore the mortality rate beyond 12 months. Further studies should also focus on the health economic aspects.

Contributors OAF planned the study, wrote the statistical analysis plan, did the data analysis, made the tables and figures and revised the manuscript. TB planned the study and revised the manuscript. LGJ planned the study and revised the manuscript. KH planned the study, did the data collection and the data analysis, wrote and revised the manuscript.

Competing interests None declared.

Ethics approval Regional Committee for Medical Research Ethics, Central Norway. Provenance and peer review Not commissioned; externally peer reviewed.

Data sharing statement № additional data available.

Open Access This is an Open Access article distributed in accordance with the Creative Commons Attribution Non Commercial (CC BY-NC 4.0) license, which permits others to distribute, remix, adapt, build upon this work non-commercially, and license their derivative works on different terms, provided the original work is properly cited and the use is non-commercial. See: http://creativecommons.org/ licenses/by-nc/4.0/

(c) Article author(s) (or their employer(s) unless otherwise stated in the text of the article) 2017. All rights reserved. No commercial use is permitted unless otherwise expressly granted.

\section{REFERENCES}

1. Haentjens P, Magaziner J, Colón-Emeric CS, et al. Meta-analysis: excess mortality after hip fracture among older women and men. Ann Intern Med 2010;152:380-90.

2. Teixeira A, Trinquart L, Raphael M, et al. Outcomes in older patients after surgical treatment for hip fracture: a new approach to characterise the link between readmissions and the surgical stay. Age Ageing 2009;38:584-9.

3. Sheehan KJ, Sobolev B, Chudyk A, et al. Patient and system factors of mortality after hip fracture: a scoping review. BMC Musculoskelet Disord 2016;17:166.

4. Klop C, Welsing PM, Cooper C, et al. Mortality in British hip fracture patients, 2000-2010: a population-based retrospective cohort study. Bone 2014;66:171-7.

5. Omsland TK, Emaus N, Tell GS, et al. Mortality following the first hip fracture in Norwegian women and men (1999-2008). A NOREPOS study. Bone 2014;63:81-6.

6. Vestergaard P, Rejnmark L, Mosekilde L. Loss of life years after a hip fracture. Acta Orthop 2009;80:525-30.

7. NICE guidelines. Hip fracture: management 2011.

8. Moja L, Piatti A, Pecoraro V, et al. Timing matters in hip fracture surgery: patients operated within 48 hours have better outcomes. A meta-analysis and meta-regression of over 190,000 patients. PLoS One 2012;7:e46175.

9. Colais P, Di Martino M, Fusco D, et al. The effect of early surgery after hip fracture on 1-year mortality. BMC Geriatr 2015;15:141.

10. Simunovic N, Devereaux PJ, Sprague S, et al. Effect of early surgery after hip fracture on mortality and complications: systematic review and meta-analysis. CMAJ 2010;182:1609-16.

11. Bohm E, Loucks L, Wittmeier K, et al. Reduced time to surgery improves mortality and length of stay following hip fracture: results from an intervention study in a Canadian health authority. Can J Surg 2015;58:257-63.

12. Larsson G, Strömberg RU, Rogmark C, et al. Prehospital fast track care for patients with hip fracture: Impact on time to surgery, hospital stay, post-operative complications and mortality a randomised, controlled trial. Injury 2016;47:881-6.

13. Alonso-Fernández $\mathrm{P}$, Romero $\mathrm{E}$, Chung $\mathrm{M}$, et al. Delayed surgery in hip fracture patients. Can we afford it? Int $J$ Health Plann Manage 2016.

14. Prestmo A, Hagen G, Sletvold O, et al. Comprehensive geriatric care for patients with hip fractures: a prospective, randomised, controlled trial. Lancet 2015;385:1623-33. 
15. Pollock FH, Bethea A, Samanta D, et al. Readmission within 30 days of discharge after hip fracture care. Orthopedics 2015;38:e7-e13.

16. Heyes GJ, Tucker A, Marley D, et al. Predictors for Readmission up to 1 Year Following Hip Fracture. Arch Trauma Res 2015;4:e27123.

17. Nordström P, Gustafson Y, Michaëlsson K, et al. Length of hospital stay after hip fracture and short term risk of death after discharge: a total cohort study in Sweden. BMJ 2015;350:h696.

18. The Norwegian Arthroplasty Register. Annual Report 2013 http:// nrlweb.ihelse.net/Rapporter/Rapport2013.pdf.

19. Rikshöft Årsrapport 2014, 2014

20. Dansk Tværfagligt Register for Hoftenære Lårbensbrud 2016, 2016.

21. Niemeijer GC, Flikweert E, Trip A, et al. The usefulness of lean six sigma to the development of a clinical pathway for hip fractures. $J$ Eval Clin Pract 2013;19:909-14.

22. Egerod I, Rud K, Specht K, et al. Room for improvement in the treatment of hip fractures in Denmark. Dan Med Bull 2010;57:A4199.

23. Kristensen MT, Kehlet $\mathrm{H}$. Most patients regain prefracture basic mobility after hip fracture surgery in a fast-track programme. Dan Med J 2012;59:A4447.

24. Sletvold O, Helbostad JL, Thingstad P, et al. Effect of in-hospital comprehensive geriatric assessment (CGA) in older people with hip fracture. The protocol of the Trondheim Hip Fracture trial. BMC Geriatr 2011:11:18.

25. Charlson M, Szatrowski TP, Peterson J, et al. Validation of a combined comorbidity index. J Clin Epidemiol 1994;47:1245-51.

26. Quan H, Sundararajan V, Halfon P, et al. Coding algorithms for defining comorbidities in ICD-9-CM and ICD-10 administrative data. Med Care 2005;43:1130-9.

27. Quan $\mathrm{H}$, Li B, Couris CM, et al. Updating and validating the Charlson comorbidity index and score for risk adjustment in hospital discharge abstracts using data from 6 countries. Am J Epidemiol 2011;173:676-82.

28. Hassani S, Lindman AS, Kristoffersen DT, et al. 30-Day Survival Probabilities as a Quality Indicator for Norwegian Hospitals: Data Management and Analysis. PLoS One 2015;10:e0136547.

29. Charlson ME, Pompei P, Ales KL, et al. A new method of classifying prognostic comorbidity in longitudinal studies: development and validation. J Chronic Dis 1987;40:373-83.

30. Gjerde AM, Aa E, Sund JK, et al. Medication reconciliation of patients with hip fracture by clinical pharmacists. European Journal of Hospital Pharmacy 2015.
31. Wolf $\mathrm{O}$, Åberg $\mathrm{H}$, Tornberg $\mathrm{U}$, et al. Do Orthogeriatric Inpatients Have a Correct Medication List? A Pharmacist-Led Assessment of 254 Patients in a Swedish University Hospital. Geriatr Orthop Surg Rehabil 2016;7:18-22.

32. Frihagen F, Grotle M, Madsen JE, et al. Outcome after femoral neck fractures: a comparison of Harris Hip Score, Eq-5d and Barthel Index. Injury 2008;39:1147-56.

33. Fine JP, Gray RJ. A Proportional Hazards Model for the Subdistribution of a Competing Risk. J Am Stat Assoc 19992012;94:496-509;94:496-509.

34. Pedersen SJ, Borgbjerg FM, Schousboe B, et al. A comprehensive hip fracture program reduces complication rates and mortality. J Am Geriatr Soc 2008;56:1831-8.

35. Husted $\mathrm{H}$. Fast-track hip and knee arthroplasty: clinical and organizational aspects. Acta Orthop Supp/ 2012;83:1-39.

36. Siu AL, Penrod JD, Boockvar KS, et al. Early ambulation after hip fracture: effects on function and mortality. Arch Intern Med 2006;166:766-71.

37. Kristensen PK, Thillemann TM, Søballe K, et al. Are process performance measures associated with clinical outcomes among patients with hip fractures? A population-based cohort study. Int $J$ Qual Health Care 2016;28:698-708.

38. Frihagen F, Nordsletten L, Madsen JE. Hemiarthroplasty or internal fixation for intracapsular displaced femoral neck fractures: randomised controlled trial. BMJ 2007;335:1251-4.

39. Guay J, Parker MJ, Gajendragadkar PR, et al. Anaesthesia for hip fracture surgery in adults. Cochrane Database Syst Rev 2016;2:CD000521.

40. Neuman MD, Rosenbaum PR, Ludwig JM, et al. Anesthesia technique, mortality, and length of stay after hip fracture surgery. JAMA 2014;311:2508-17.

41. Basques BA, Bohl DD, Golinvaux NS, et al. Postoperative length of stay and 30-day readmission after geriatric hip fracture: an analysis of 8434 patients. J Orthop Trauma 2015;29:e115-20.

42. Muhm M, Hillenbrand H, Danko T, et al. [Early complication rate of fractures close to the hip joint. Dependence on treatment in on-call services and comorbidities]. Unfallchirurg 2015;118:336-46.

43. Biau DJ, Latouche A, Porcher R. Competing events influence estimated survival probability: when is Kaplan-Meier analysis appropriate? Clin Orthop Relat Res 2007;462:229-33. 